\title{
Editorial
}

\section{ENSURING A FUTURE FOR OPEN-ACCESS PUBLISHING}

\section{T}

1 HE Journal of Ethics and Social Philosophy (JESP) was founded in 2005 by Andrei Marmor, James Dreier, Julia Driver, and David Estlund, with the financial and technical support of the UsC Gould School of Law and the UsC Dana and David Dornsife College of Letters, Arts and Sciences, in which Marmor held joint appointments. The vision of JESP, then and now, is to provide a model for a directly university-funded, completely open-access publication at the very highest standard of peer review. JESP's aspiration is to show how a journal can be at once one of the most well-run and most prestigious places to publish leading work in the fields of social, political, and legal philosophy and ethics, broadly construed, while doing so at zero cost to authors or readers, allowing for fast, easy publication with worldwide impact.

The rationale for the directly university-funded, open-access model is simple. The original rationale for the existence of journals was to disseminate research, and subscription costs were justified to support the expenses of dissemination, which for print journals were quite substantial on the margin. Over time, the peer-review structure of journals has come to play a second function-that of establishing a well-respected standard to help readers judge which articles are worth their attention and assist universities in evaluating the production of their scholars. Third, in an age of vast circulation of prepublished drafts, journal publication establishes a settled, final version of any piece of work for reference and discussion. University-funded open access is premised on the assumption that, given the advent of electronic publication and subsequent reduction in the marginal costs of dissemination, the first rationale for journals comes apart from the second and third. JESP is built on the understanding that any author can easily offer their own work for free access on their own website. Our role is not to provide access, but to set a standard of excellence that can call attention to work and establish a fixed record of that work.

Although the marginal costs of dissemination of any individual article is zero, JESP does bear the costs of evaluation of each submission and production of each accepted article. Every submitted paper is handled by a paid managing ed- 
itor; every paper that goes out for review costs time and money to handle correspondence with possible referees; and every paper goes through copyediting and typesetting at the cost of both time and money. These costs don't go away in the era of electronic publishing, but the founders of JESP believed and still believe that bearing these costs falls under the central mission of modern research universities - the production and dissemination of knowledge. JESP has been blessed that USC administrators have shared this vision and are committed to permanent support of the journal.

The benefits of open-access publishing are I think made clear by JESP's record. JESP published ten full articles in 2005-2006-the journal's first two years of publication - that have been downloaded more than 117,500 times - an average of more than one thousand per full year of publication, per article. Articles published so far in 2017 have been downloaded at an average rate of 278 times per month. Downloads are of course only one possible measure of reach, and most downloads vastly overrepresent actual readership. But the free availability of articles in JESP means that they may be read by scholars around the globe whose institutions cannot afford access to a subscription journal—and without imposing up-front costs on authors, many of whom are early-career scholars without access to research funds that could underwrite open-access fees at subscription journals. Even readers who have institutional access will in many cases find it easier to link directly to JESP from any device, without the need to log in through their institution or through a VPN client, which makes JESP articles more likely to be downloaded and read.

So it is no surprise that the ten full articles published by JESP in 2005-2006 have between them garnered more than 375 citations, according to Google Scholar-an average of 37.5 citations - and seven of them have been cited fifteen or more times. The five invited articles published as a symposium on Joseph Raz's "The Myth of Instrumental Rationality" have another sixty-seven citations; two of them have been cited at least thirty times. These are strong measures of impact for any philosophy journal over this period-compare that the first ten articles published in The Journal of Philosophy starting in April 2005 have totaled only 140 citations despite that journal's towering reputation established over more than a century. This suggests not only that JESP's model provides an important service to the profession, but also that its model is in the best interests of authors who want their work to be read and engaged with.

I have been blessed to work with JESP in every possible role-as reader, author, referee, associate editor, and now editor-in-chief. In 2005, JESP's founding year, I was invited to participate in JESP's first symposium, on Joseph Raz's article, "Instrumental Rationality." I also submitted an original self-standing article to 
JESP that year, "Cudworth on Normative Explanations," which I still believe to be the best paper that I have ever written. The following year I joined the USC faculty and became a regular referee for JESP, refereeing twelve papers over three to four years before being asked to serve as associate editor for discussion notes in 2009. In December 2014, I took over from Andrei Marmor as editor-in-chief in order to ensure continuity for JESP, as he planned for his departure from USC to a new position at Cornell University.

JESP'S university-funded, open-access model comes with risks. So far as I know, JESP was the first leading, open-access philosophy journal to successfully go through a change in leadership, passing one of the first tests of a journal for institutional continuity that exceeds the personal investment of its founders. In addition, depending on direct university funding requires regularly seeking renewed commitments from university administrators, and the risks that this funding stream can depend too much on the involvement of particular individuals, with particular faculty appointments.

This year, JESP passed one more test to ensure continuity over time. Since its founding, it has been run on UsC Gould School of Law servers using software originally developed by Gould IT staff. That software became obsolete over time, and with Marmor's departure and turnover in the Gould IT staff, it is no longer possible to maintain the journal using that system. So JESP has moved to a new online management system, the Open Journal System developed by the Public Knowledge Project, which facilitates effective management of open-access journals at a reasonable cost. Transferring JESP to the oJS has been labor-intensive but will ensure a stable future for the journal. It gives us greater functionality, and will be easier to maintain for the future. Along with this transition we have incorporated many other changes that will ensure the long-term accessibility of work published in JESP.

Among these changes, we are getting a new look-on the website and on the (electronically) printed page. When you visit jesp.org, you will now see a cleaner, easier-to-navigate site, with an updated JESP logo. You will find it easier to register as a user and volunteer to be a reviewer for JESP, find the content that you are looking for, and share JESP content on social media. JESP discussion notes, which were not an original feature of the journal and originally were not assigned to journal issues, have now been assigned to designated journal issues under a separate section for discussion notes, and past as well as future discussion notes can be found in this way, making them easier to cite following more standard conventions.

For JESP articles starting with volume XII, issue 1, Matthew Silverstein, Associate Professor of Philosophy at NYU Abu Dhabi, has volunteered his typesetting 
skills and experience in order to produce a more polished look for the journal. Although JESP has always collected articles into volumes and issues, you will also find that we now take the division into volumes and issues more seriously; articles will carry continuous pagination across each volume as in traditional print journals; each journal issue is now designated with a unique jacket cover; and journal issues can be downloaded as unique PDF files, complete with a table of contents for that issue.

In summer 2016, JESP updated its editorial board, dropping a few inactive members and adding eight new members to increase energy and diversity of representation across geography, race, gender, field of expertise, career stage, and institutional affiliation. JESP is fortunate to have the continued support of its distinguished editorial board, and will continue to seek out new representatives over the coming years to more fully show distinction across the range of fields and institutions in which and from which we seek to publish the very best work. The full list of editorial board members can be found on the journal's website.

JESP continues to face challenges looking forward. Here I will single out just two. As I have already noted, in 2009 JESP added a discussion notes section in response to a perceived need for more places to publish short articles in philosophy. The need for this forum has been fully demonstrated by the response, as the number of discussion articles published in JESP now rivals the number of main articles. But we have found that the authors submitting discussion articles to JESP have been far less diverse in gender and areas of research than authors submitting main articles. One of JESP's major objectives over the coming years is to appeal, particularly in the discussion notes section, to a much wider range of submitting authors.

A challenge we look forward to at JESP is securing more submissions in fields that fall under the label of "social philosophy," broadly construed, including philosophy of race, gender, and extra-political institutions like the family. JESP has published what I believe to be great work in these areas, including Anca Gheaus's article, "Gender Justice" (volume vI, issue 1); Jeremy Dunham and Holly Lawford-Smith's "Offsetting Race Privilege" (volume XI, issue 2); Luara Ferracioli's and Anca Gheaus's articles about children; and Joachum Wundisch and Vuko Andric's article on disability. But this falls far out of proportion with the role of "social philosophy" in the journal's title, and we hope to publish much more such work, and to find authors interested in publishing it in JESP.

Journal editorial work is a thankless task-virtually every day I put time into it and am reminded that it is by far my least favorite part of my job. It involves endless unpaid and unappreciated work, mostly having to judge the work of other philosophers. I have many constituents to please, and many ways of giving 
them reasons not to be pleased. Authors expect prompt decisions and instructive justifications given for those decisions, referees expect their recommendations to be followed, and readers expect that work should be published in JESP only if it meets their own high standards. As editor-in-chief, I try to balance all of these demands and more, and depend at every stage on a hardworking and underappreciated team of associate editors, the enthusiasm of prospective authors for publishing their work in JESP, and the reliability and trustworthiness of hundreds of referees around the globe, many of whom I do not know, but who put substantial work into our unsolicited refereeing requests. It is not a perfect process, and it can go wrong in many ways, but we do our best, and each day, we try to do better-both at establishing a process that will produce the best results, and at respecting that process. We think we are doing well, but we would like to be the best, and we believe we can be. Thanks for your patience with us, and your continuing support for JESP and its mission.

Mark Schroeder EDITOR-IN-CHIEF 